\title{
PERFORMANCE OF COUPLING BEAMS WITH OPENINGS EXPOSED TO CYCLIC LOADING
}

\author{
Hesham A. Haggag ${ }^{1}$, Wael M. Hassan², Abd El-Azim Sayed ${ }^{3}$ \\ ${ }^{1}$ Professor of Structural Engineering, Civil Engineering department, Faculty of Engineering, Helwan University, \\ Egypt, E-mail: hahaggag@gmail.com \\ ${ }^{2}$ Associate Professor, Structural Engineering, Housing and Building National Research Center, Egypt \\ E-mail: whassan@berkeley.edu \\ ${ }^{3}$ Researcher, Faculty of Engineering, Helwan University, Egypt \\ E-mail: abdelazim@live.com
}

\begin{abstract}
The performance of coupling beams under cyclic loadings is evaluated when they have openings with different configuration. The study is performed through experimental examination on four reduced scale coupling beams. The testing is done in the Concrete Laboratory at the Housing and Building National Research Center, Cairo, Egypt. Square openings are constructed on three specimens with different configurations whereas the fourth specimen kept without openings for the comparison matter. Two openings are fabricated at top and bottom of the diagonal bars in one beam specimen. Another specimen contains two openings at left and right of the diagonal bars. The last specimen has four square openings placed at top-bottom and left-right of the diagonal bars of the coupling beam. The yield and ultimate tensile strength of the reinforcement steel bars are 510 and $720 \mathrm{MPa}$, respectively with elastic modulus of $200 \mathrm{GPa}$. The concrete characteristic strength is $38 \mathrm{MPa}$. All specimens were tested under laterally cyclic loading to simulate the subjected loads on coupled shear walls. A special complicated setup is utilized for that issue. The results are recorded during testing and at the end of each cycle. The forcedeformation relationships are recorded and their corresponding hysteresis loops are plotted. The cracks patterns are also marked and recorded. From the obtained results, one may observe that, in case of using two openings located at right and left (near the shear walls), the stiffness of the coupling beam is slightly decreased. The coupling beams stiffness is decreased by $\sim 8.5 \%$ for the other pattern of two openings and by $\sim 13.5 \%$ in case of using four openings.
\end{abstract}

KEYWORDS: Coupling beam, Shear behavior, Openings, Cyclic loading. 


\section{INTRODUCTION}

Reinforced concrete cores or shear walls may contain openings to accommodate doorways. Accordingly, connected beams are found over those pass ways. Shear walls with those coupling beams form an efficient system to resist lateral loads in tall buildings. A well-designed coupling beams could improve the stiffness of the connected shear walls and considerably enhance their energy dissipation capacity. The stiffness of the coupling beams is increased with decreasing the span to depth ratio of the coupling beams. Building with coupled shear walls may have good energy dissipation through cracks formed in the coupling beams. Those coupling beams work as fuses to dissipate energy through the large inelastic rotations. A well detailed reinforcement of a coupling beam enhances the coupling action between their shear walls. So, it is required to design the coupling beams carefully to achieve a desired degree of coupling and level of energy dissipation. The degree of coupling of this system affects directly the shear walls reactions and the internal forces due to the lateral forces. According to the ACI 318-19 code $^{[1]}$, the coupling beam with aspect ratio $(\mathrm{Ln} / \mathrm{h}<2)$ shall be reinforced with two intersecting groups of diagonally placed bars symmetrical about the mid-span. These two groups of diagonal bars and the concrete they encase, are commonly assumed to form a truss, one of these two groups acting as the tension member and the other as the compression member. To improve the compressive strength of the diagonal truss members as well as resisting buckling of the diagonal bars in case of compression, use of transverse reinforcement around the diagonal bar groups is required (ACI 318-19) ${ }^{[1]}$. Nominal transverse reinforcement also is required around the entire beam cross section. Design of diagonally-reinforced concrete coupling beams are given in ACI 318-19, S18.10.7 ${ }^{[1]}$. The strength of beams with diagonal reinforcement is determined by ACI 318-19 ${ }^{[1]}$ as represented here in Eq.1:

$$
\begin{gathered}
V_{n}=2 A_{v d} f_{y} \sin \propto \leq 0.83 \sqrt{f_{c}^{\prime}} A_{c w} \quad \text { (SI } \quad \text { Eq.1 } \\
\text { units) }
\end{gathered}
$$

Where $V_{n}$ refers to nominal shear capacity of beam, $A_{v d}$ is the reinforcement area of one group of diagonals, $\mathrm{f}_{\mathrm{y}}$ is the yield strength of the reinforcement and $\alpha$ is the angle of inclination of the diagonal bars with beam center line. It is observed that shear strength is based only on the vertical components of the area of diagonals reinforcement. According to ACI codes, there are two permitted options for confinement of the beam reinforcement, diagonal and full section confinement. In case of using diagonal confinement, the transverse reinforcement is required to satisfy S18.7.5.2 (a) through (e) and being placed around bars of each diagonal with minimum required longitudinal and transverse reinforcement around the beam crosssection. The required area of transverse reinforcement, $A_{\text {sh }}$ is not less than the greater of (i) and (ii) as represented in Eq.2 and Eq.3. 
Ash = bigger of $\left\{\begin{array}{cc}0.09 s b_{c} \frac{f_{c}^{\prime}}{f_{y t}} & \mathbf{E q . 2} \\ 0.3 s b_{c}\left(\frac{A_{g}}{A_{c h}}-1\right) \frac{f_{c}^{\prime}}{f_{y t}} & \mathbf{E q . 3}\end{array}\right.$

Where s refers to the longitudinal spacing of the transverse reinforcement, $b_{c}$ refers to the cross-sectional dimension of core measured to the outside edges of the transverse reinforcement composing area $\mathrm{A}_{\mathrm{sh}}, \mathrm{A}_{\mathrm{g}}$ is the gross area of concrete section and $A_{c h}$ is the cross-sectional area measured to the outside edges of the transverse reinforcement. Previously, the behavior of these beams with cyclic loading was studied with different parameters by many researchers. Sometimes, openings or slots in existing coupling beam are required for passing some ducts as shown in Figure 1 which may lead to a reduction in their stiffness; and subsequently undesired behavior for cyclic loading. Structural engineers tend to allow HVAC and MEP ducts in coupling beams without quantifying their possible negative effect on the seismic performance so the behavior of reinforced concrete coupling beams that exposed to pass ducts through openings in its body with different number and location needs more classification and study.

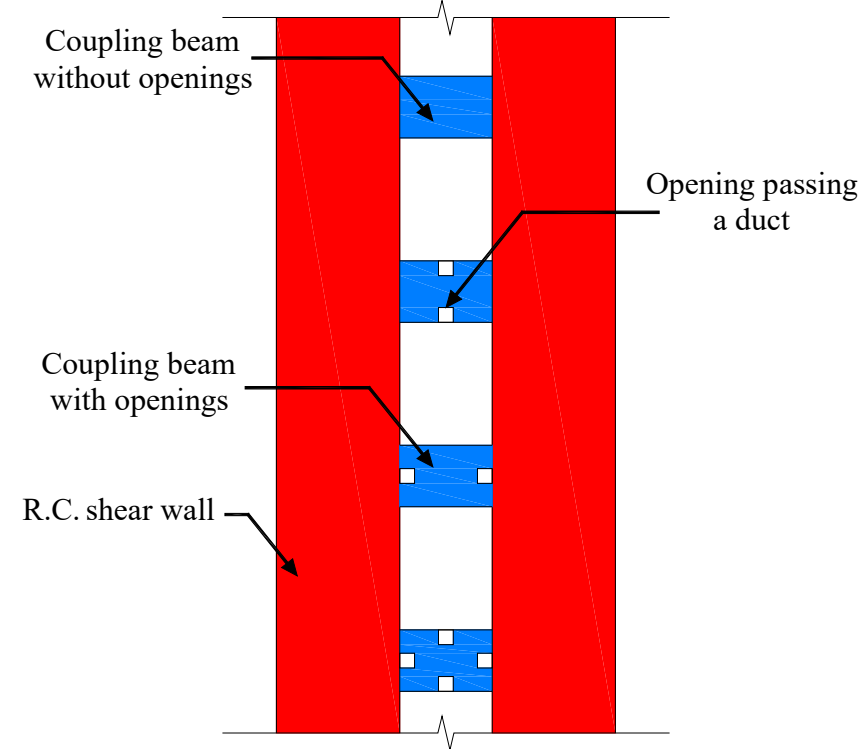

Figure 1: Coupling beams with different number and position of openings.

\section{OBJECTIVE}

The primary objective of this research is to study the seismic behavior of coupling beams with openings to quantify their effect on the overall structural performance of these beams. The objectives are itemized as:

- Evaluation of the cyclic response of coupling beams with openings under cyclic lateral loads.

- Investigate the effect of changing the opening locations on the characteristics of the coupling beams.

- Assessment of strength and plastic rotation of coupling beams with openings till failure. 
- Evaluation of the ductility and effective stiffness of coupling beams with openings.

- Recommendation to coupling beams designers are assessed.

\section{EXPERIMENTAL PROGRAM}

The experimental investigation includes testing of four specimens which are designed according to the ACI 318-19 ${ }^{[1]}$ code. The beams are built with dimensions of $450 \times$ $350 \times 200 \mathrm{~mm}$ and reinforced diagonally by $4 \mathrm{~T} 16$ for each group with $11 \mathrm{~T} 10 / \mathrm{m}$ diagonally confinement reinforcement. Longitudinal reinforcement of 2T10 are placed in the top and bottom of specimens. The test parameters are presented to investigate the behavior of the coupling beams when they have openings. The experimental program comprised casting, testing and analysis of four beams, three beams with openings and one reference specimen without openings. Formed openings with square shape of $60 \times 60 \mathrm{~mm}$ were used in the coupling beams with different numbers and locations are as shown in Figure 2, that are named laterally according to the beam position during testing. Table 1 shows the details of the tested specimens whereas, Figure 3 presents the concrete dimension and Figure 4 represents reinforcement details of the specimens. Compressive strengths of concrete cubes are presented in Table 2.
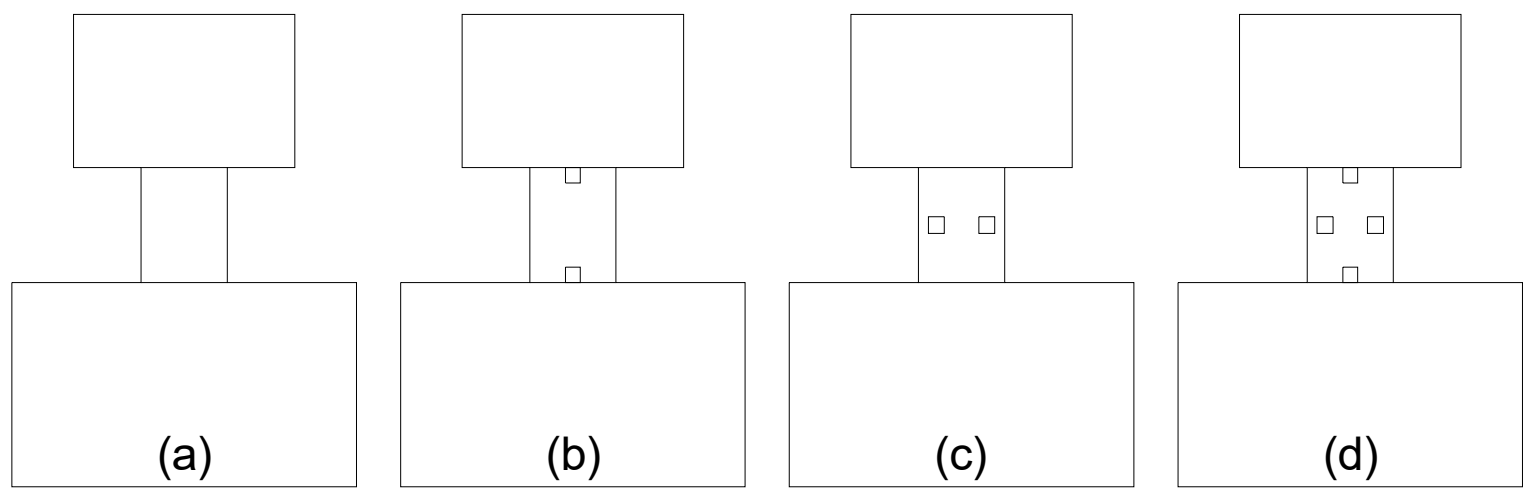

Figure 2: Opening locations in the coupling beam: (a) no openings, (b) top and bottom, (c) right and left and (d) top, bottom, right and left.

Table 1: Test matrix.

\begin{tabular}{|c|c|c|c|c|c|}
\hline $\begin{array}{c}\text { Specimen } \\
\text { label }\end{array}$ & $\frac{L_{n}}{h}$ & $\begin{array}{l}\text { Span } \\
(\mathrm{mm})\end{array}$ & $\alpha$ (deg.) & $\begin{array}{c}\text { Diagonal } \\
\text { reinforcement }\end{array}$ & $\begin{array}{c}\text { Opening } \\
\text { arrangement }\end{array}$ \\
\hline LB13-00 & \multirow{4}{*}{1.29} & \multirow{4}{*}{450} & \multirow{4}{*}{25.72} & \multirow{4}{*}{$4 \mathrm{~T} 16$} & 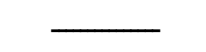 \\
\hline LB13-TB & & & & & $\mathrm{T}$ and $\mathrm{B}$ \\
\hline LB13-RL & & & & & $\mathrm{R}$ and $\mathrm{L}$ \\
\hline LB13-TBRL & & & & & $\mathrm{T}, \mathrm{B}, \mathrm{R}$ and $\mathrm{L}$ \\
\hline
\end{tabular}




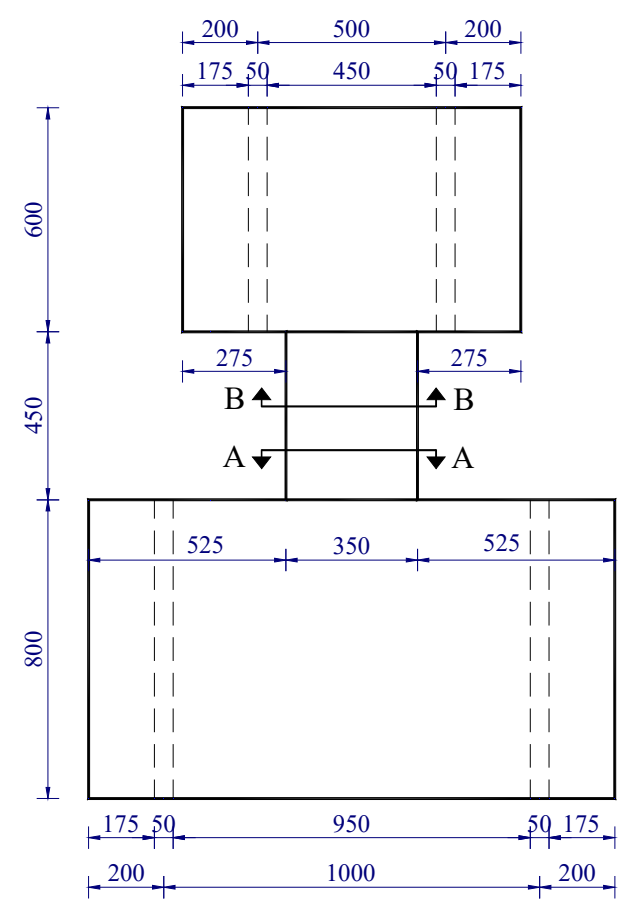

Elevation

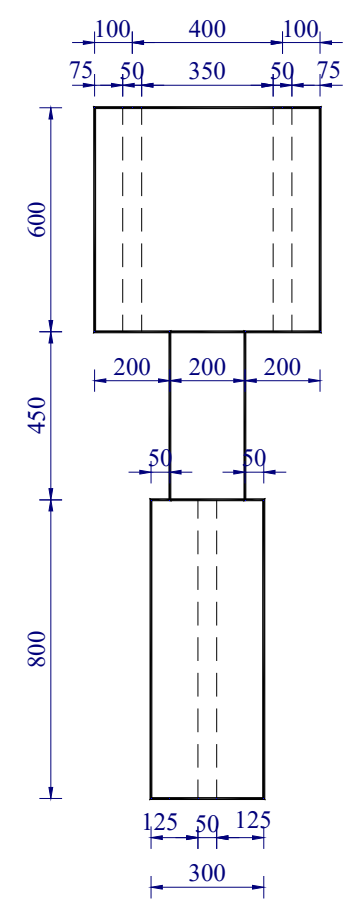

Side View
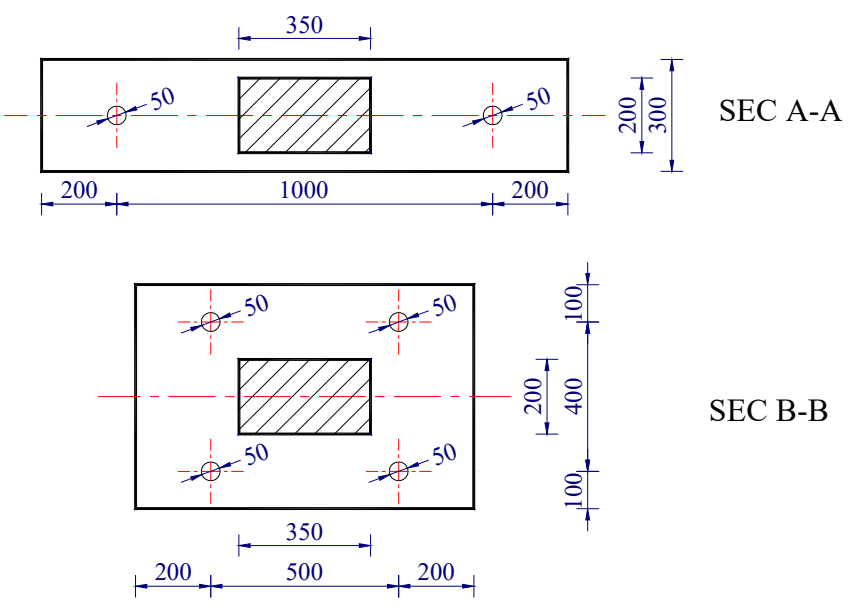

Figure 3: Concrete dimensions for specimen LB13-00.

Table 2: Different compressive strength of concrete cubes.

\begin{tabular}{|c|c|c|c|c|}
\hline \multicolumn{5}{|c|}{ Compressive strength for cubes (MPa) } \\
\cline { 1 - 2 } Specimen No. & $\mathbf{7}$ days & Average & $\mathbf{2 8}$ days & \multirow{2}{*}{ Average } \\
\hline LB13-00 & 30.1 & & 38.17 & \\
\cline { 1 - 2 } LB13-TB & 29.8 & \multirow{2}{*}{29.8} & 41.04 & \multirow{2}{*}{38.25} \\
\cline { 1 - 2 } LB13-RL & 28.9 & & 38.05 & \\
\cline { 1 - 2 } LB13-TBRL & 30.3 & & 35.75 & \\
\hline
\end{tabular}



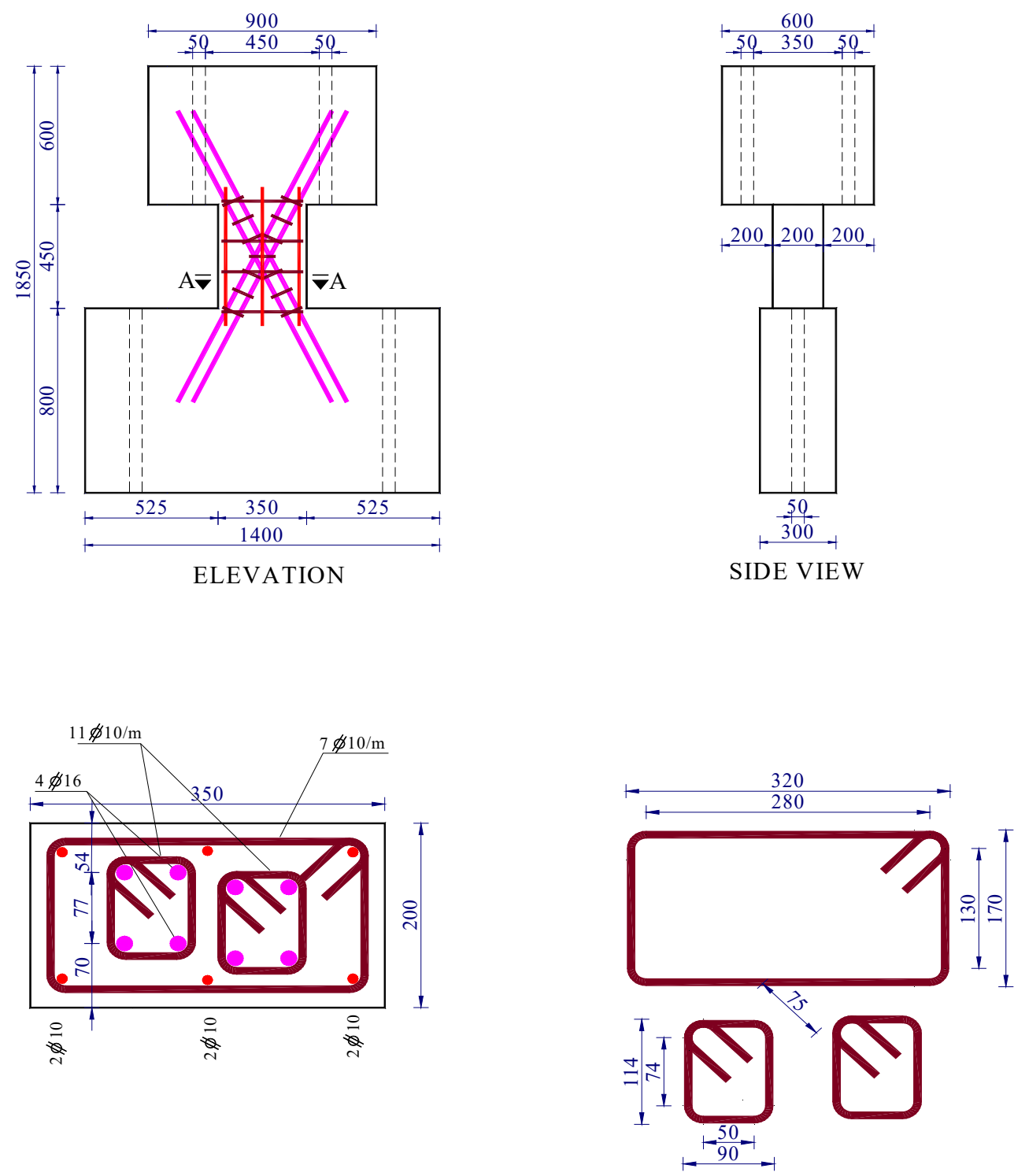

SEC A-A

Figure 4: Reinforcement details of specimen LB13-00 (dimensions are mm).

\subsection{Test Setup}

There are many systems for the test setup that could be used for some of previous researches. The suitable test setup that used in this research according to capabilities in the Reinforced Concrete Laboratory of the Housing and Building National Research Center (HBNRC) in Cairo as shown in Figure 5. The structural loading frame in the reinforced concrete laboratory of the HBNRC in Cairo was used for the testing. In addition, a steel frame consisting of two leg I-beams weld-connected as $\mathrm{L}$ shape with shown dimensions in Figure 6 was used to transport the load from the cyclic actuator to the supported specimen. The specimens were fixed anchored to the reaction floor by two big bolts. Then the $\mathrm{L}$ frame was rested and fixed on top of it. 

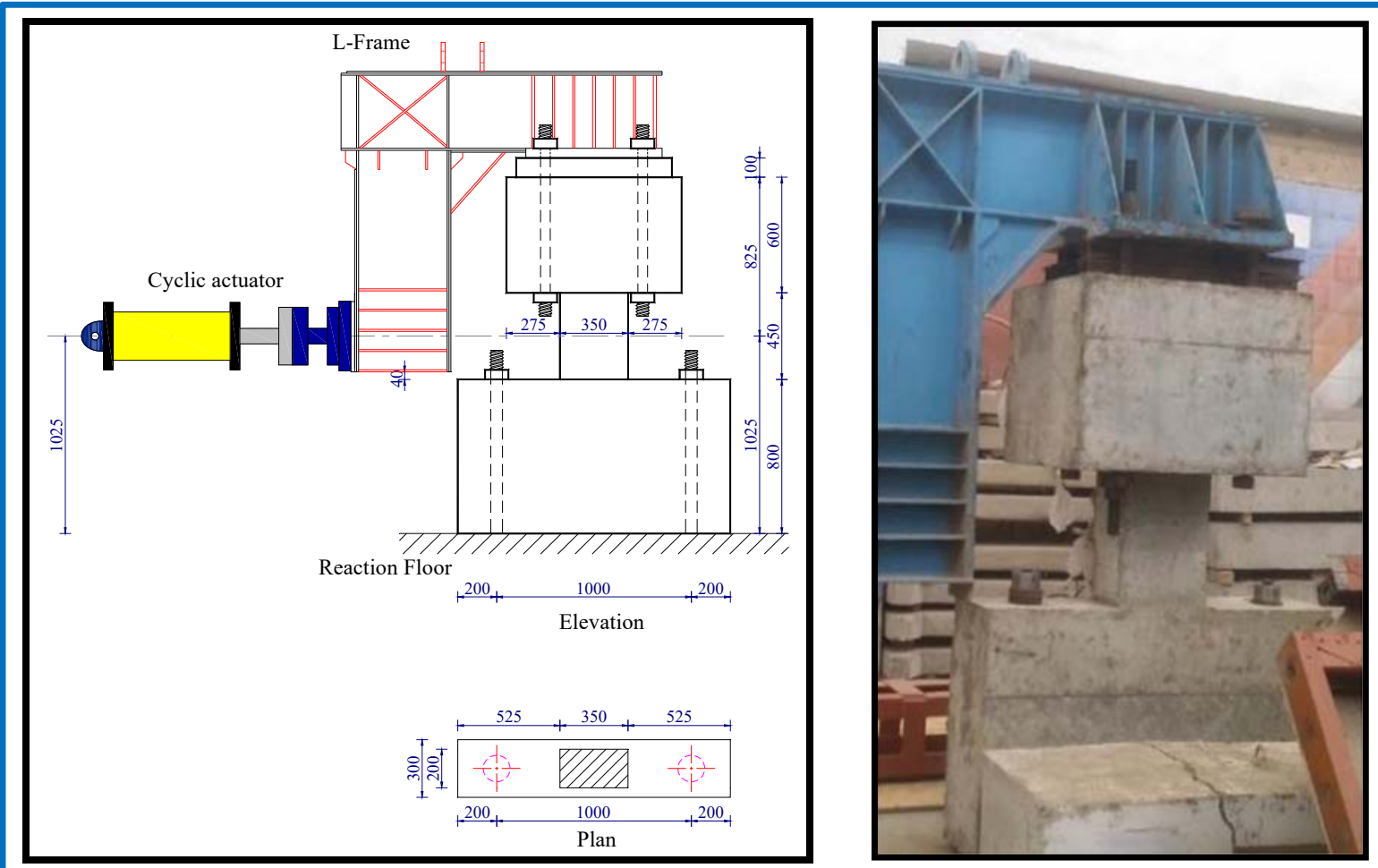

Figure 5: Test setup (all dimensions are $\mathbf{m m}$ ).

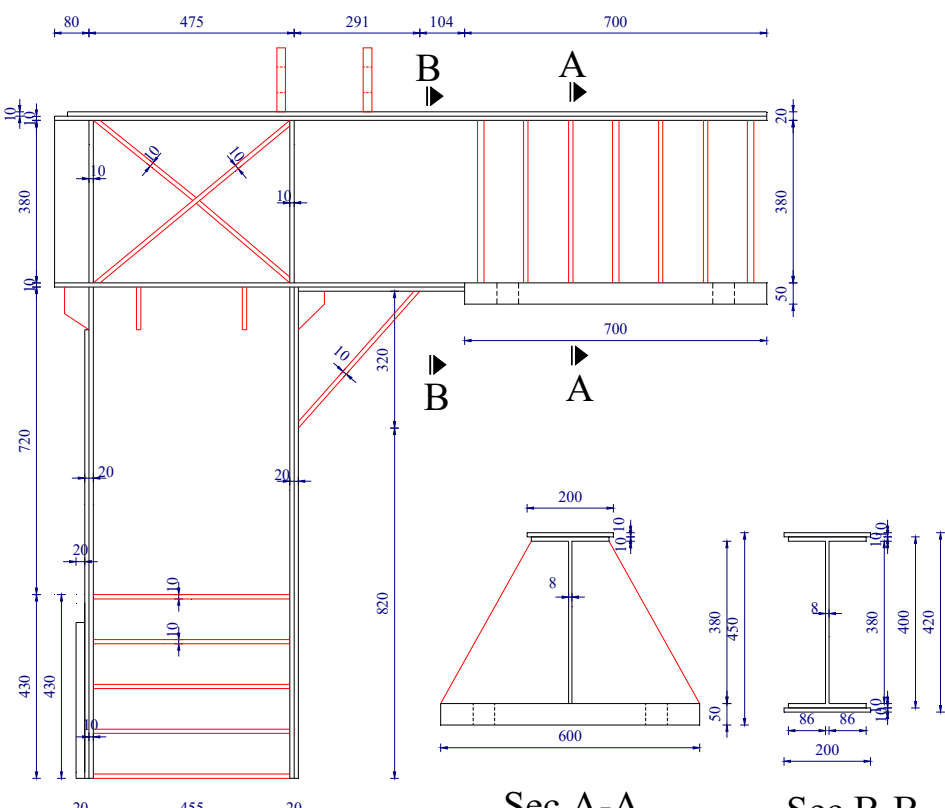

Figure 6: Dimensions of L-frame of test setup (all dimensions are mm).

\subsection{Loading Protocol}

The load was transmitted to the specimen from the actuator by the L-Frame which was previously fixed with it. The actuator was supported and placed horizontally at a level such that the actuator force passes through the mid-span of the coupling beam specimen to achieve zero moment at beam mid-span and a skew symmetric bending moment and deflection for specimen, mimicking realistic conditions. The testing procedure comprised displacement-controlled cycle reversals as shown in Table 3 and Figure 7. 
Table 3: Displacement protocol (mm).

\begin{tabular}{|c|c|c|c|c|c|c|c|c|c|c|c|}
\hline $\begin{array}{l}\text { Cycles } \\
\text { group \# }\end{array}$ & Step & disp. $(\mathrm{mm})$ & $\begin{array}{c}\text { Cycles } \\
\text { group \# }\end{array}$ & Step & $\operatorname{disp} .(\mathrm{mm})$ & $\begin{array}{l}\text { Cycles } \\
\text { group \# }\end{array}$ & Step & $\operatorname{disp} .(\mathrm{mm})$ & $\begin{array}{c}\text { Cycles } \\
\text { group \# }\end{array}$ & Step & $\operatorname{disp} .(\mathrm{mm})$ \\
\hline \multirow{6}{*}{1} & 1 & -1 & \multirow{6}{*}{3} & 13 & -3 & \multirow{6}{*}{5} & 25 & -6 & \multirow{4}{*}{7} & 37 & -13.5 \\
\hline & 2 & 1 & & 14 & 3 & & 26 & 6 & & 38 & 13.5 \\
\hline & 3 & -1 & & 15 & -3 & & 27 & -6 & & 39 & -13.5 \\
\hline & 4 & 1 & & \begin{tabular}{|l|}
16 \\
\end{tabular} & 3 & & 28 & 6 & & \begin{tabular}{|l|}
40 \\
\end{tabular} & 13.5 \\
\hline & 5 & -1 & & 17 & -3 & & 29 & -6 & \multirow{4}{*}{8} & 41 & -20.25 \\
\hline & 6 & 1 & & 18 & 3 & & 30 & 6 & & 42 & 20.25 \\
\hline \multirow{6}{*}{2} & 7 & -2 & \multirow{6}{*}{4} & 19 & -4 & \multirow{6}{*}{6} & 31 & -9 & & 43 & -20.25 \\
\hline & 8 & 2 & & 20 & 4 & & 32 & 9 & & 44 & 20.25 \\
\hline & 9 & -2 & & 21 & -4 & & 33 & -9 & & & \\
\hline & 10 & 2 & & 22 & 4 & & 34 & 9 & & & \\
\hline & 11 & -2 & & 23 & -4 & & 35 & -9 & & & \\
\hline & 12 & 2 & & 24 & 4 & & 36 & 9 & & & \\
\hline
\end{tabular}

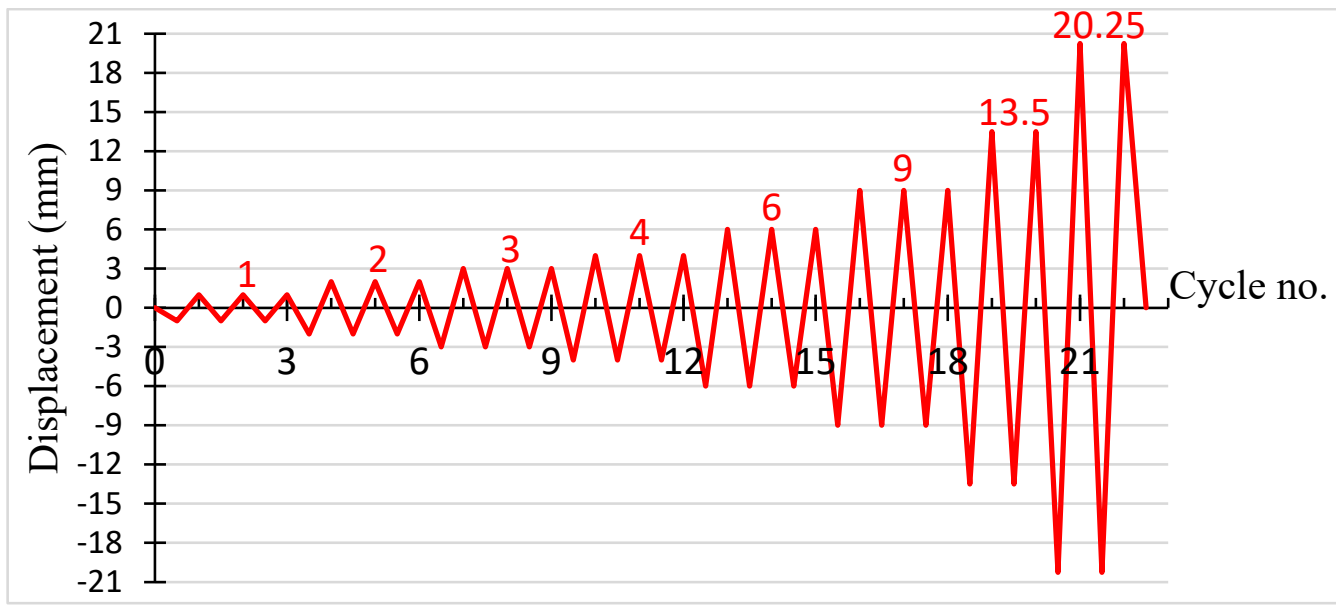

Figure 7: Cyclic displacement protocol chart (mm).

\subsection{Measurements}

Horizontal deflection was measured at two points in each specimen at upper and lower end blocks, at heights of $400 \mathrm{~mm}$ and $1550 \mathrm{~mm}$ as shown in Figure 8 to control the displacement protocol. Moreover, another 7 LVDTs were connected in different locations for comparison with the analytical measurements. These measurements are done by using Linear Variable Displacement Transducers (LVDTs). For each load increment, the load was applied via the hydraulic cyclic jack and kept constant until the readings of the dial gauges were recorded; then the next load increment was applied. The strains in the reinforcement bars are also measured during testing. Strain gauges are attached to the bar surfaces. Twelve strain gauges are installed on the bars at locations as shown in Figure 9 for the solid Specimen (LB13-00) and five strain gauges at locations as shown in Figure 10 and Figure 11 for other specimens that had openings. 


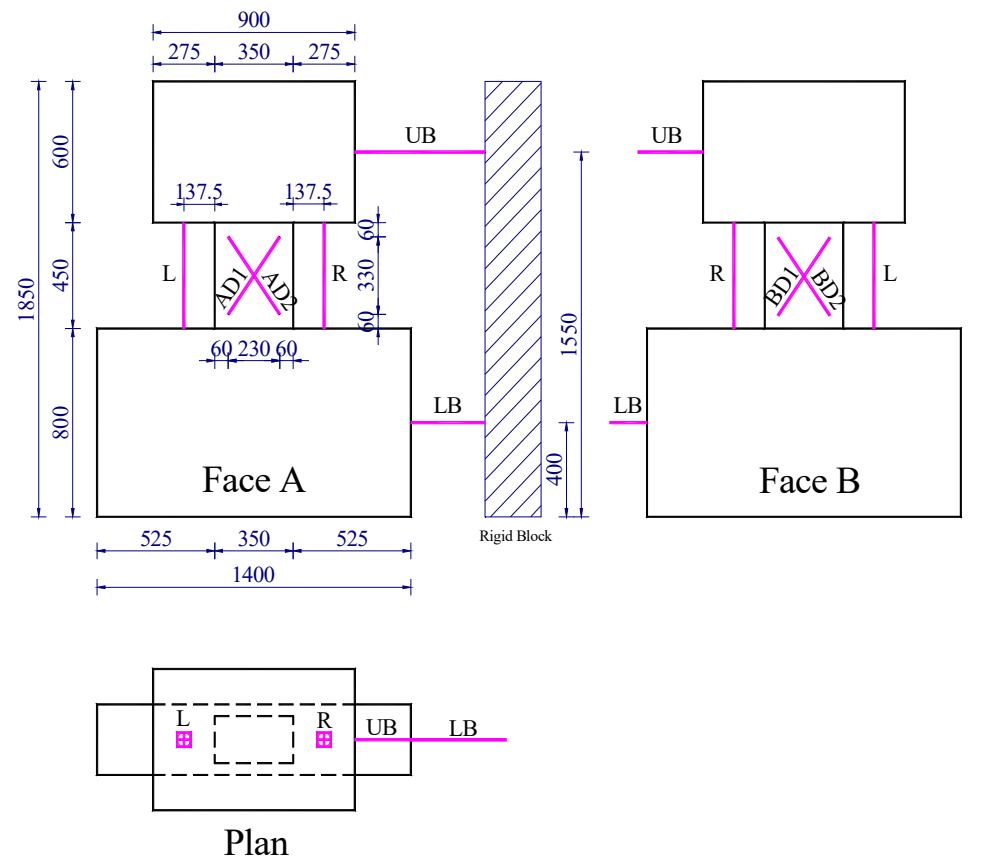

Figure 8: Distribution of LVDTs for all specimen (dimensions are mm).
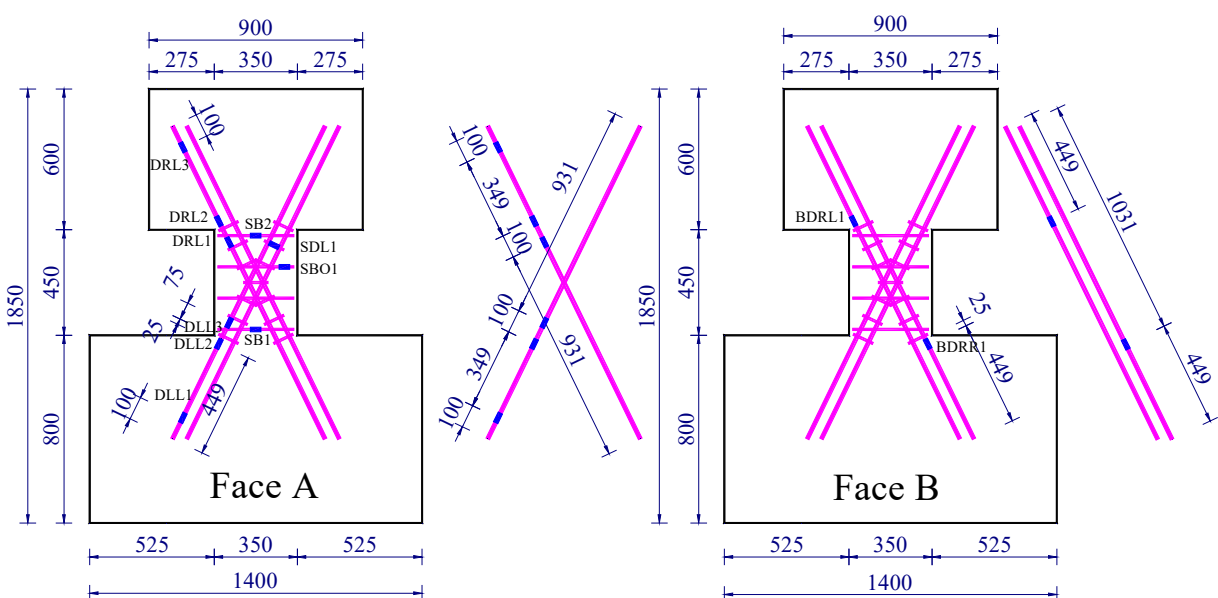

Figure 9: Strain gauge locations for specimen LB13-00 (dimensions: mm).

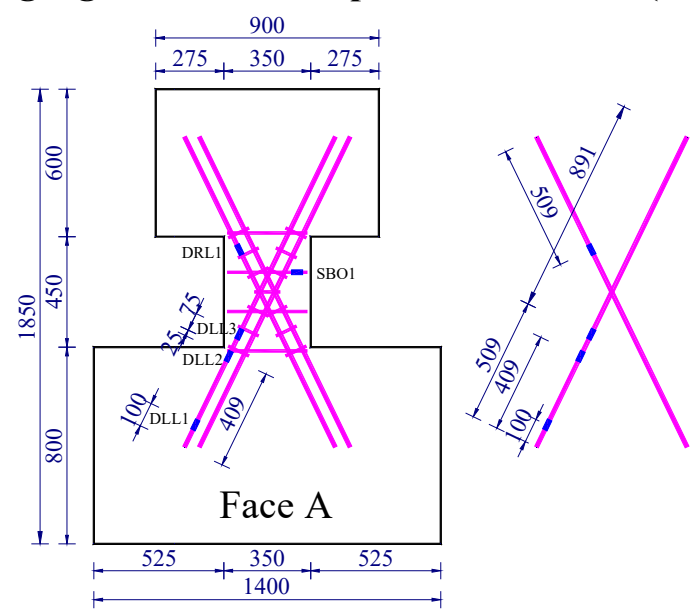

Figure 10: Strain gauge locations for specimens having openings (mm). 


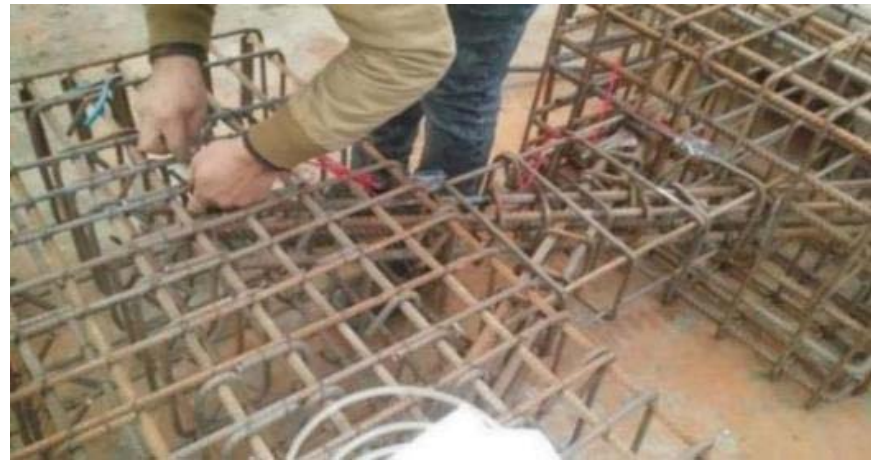

Figure 11: Fixing strain measurements.

\section{EXPERIMENTAL RESULTS}

All specimens were tested under cyclic loading and the cyclic load was gradually increased till failure. The measurements of the deflections from the LVDTs were recorded during the steps of loadings. Also, the cracks propagated along the coupling beam surface were marked and recorded. The results of such measurements are presented below.

\subsection{Crack Patterns}

It was observed that at early loading stages slip/extension cracks initiated specifically at beam chord rotation of $0.4 \%$ and then started to spread. The shear cracks initiated at $\sim 4 \mathrm{~mm}$ relative displacement ( $0.9 \%$ beam chord rotation). The cracks were marked during the testing loading steps. Figure 12 and Figure 13 show the cracks pattern for each specimen at 4\% beam chord rotation. Studying those figures showed that all specimens experienced shear failure.

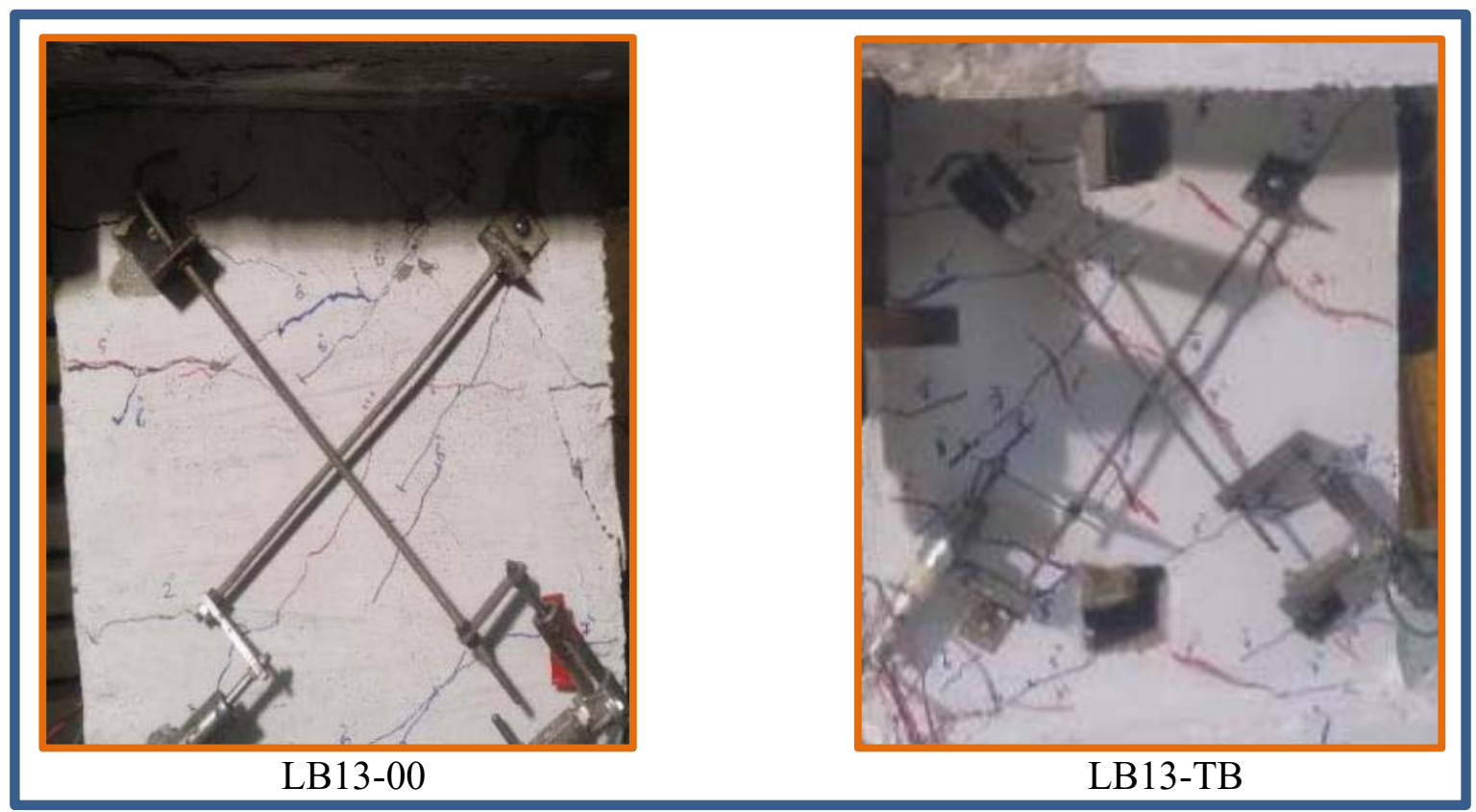

Figure 12: Cracks pattern for specimens $L B 13-00$ and $L B 13-T B$ at $4 \%$ beam chord rotation. 


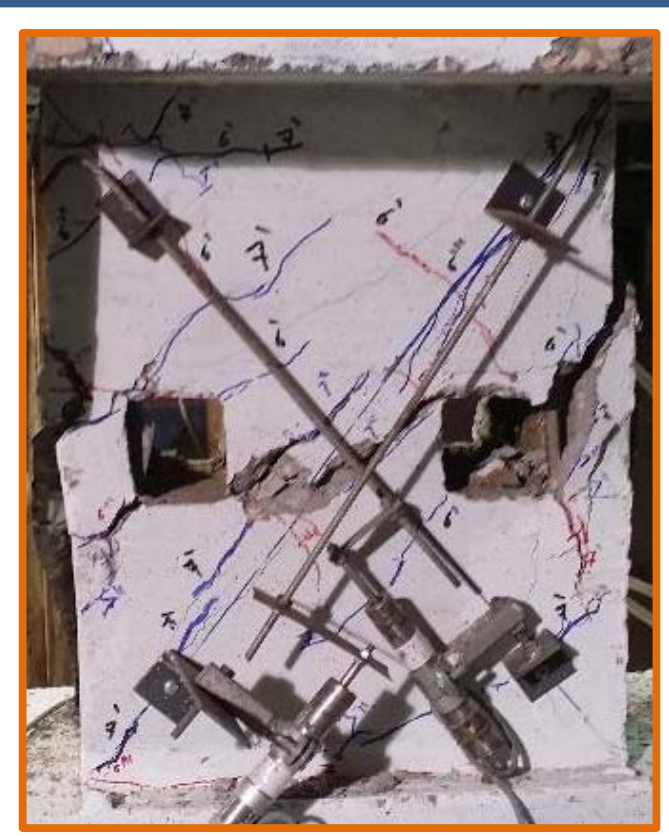

LB13-RL

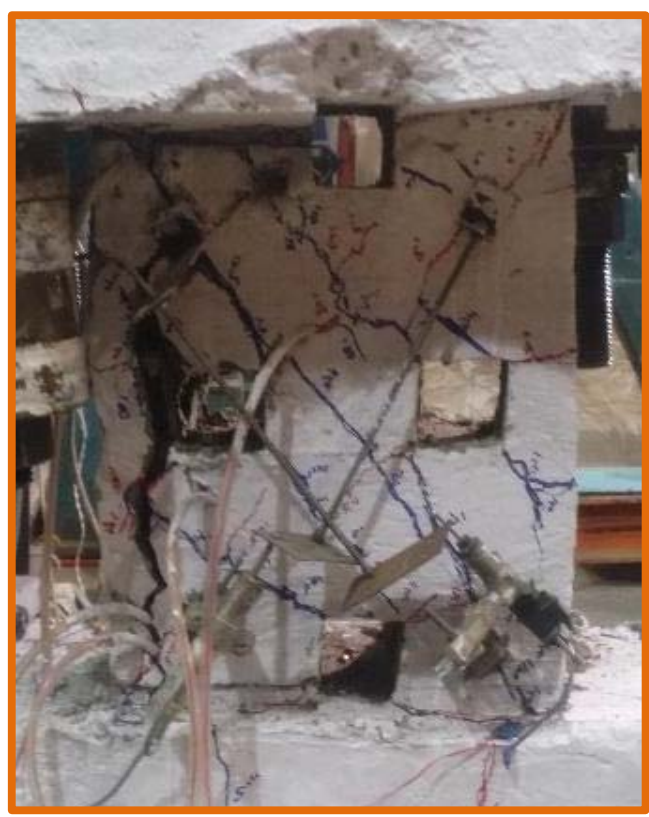

LB13-TBRL

Figure 13: Cracks pattern for all specimens LB13-RL and LB13-TBRL at 4\% beam chord rotation.

\subsection{Load Displacement Relations}

The load-displacement responses and envelope curves of the tested specimens were recorded during the test and plotted as shown from Figure 14 to Figure 21. All tests stopped after the $7^{\text {th }}$ stage of load cycles with displacements higher than $13.5 \mathrm{~mm}$.

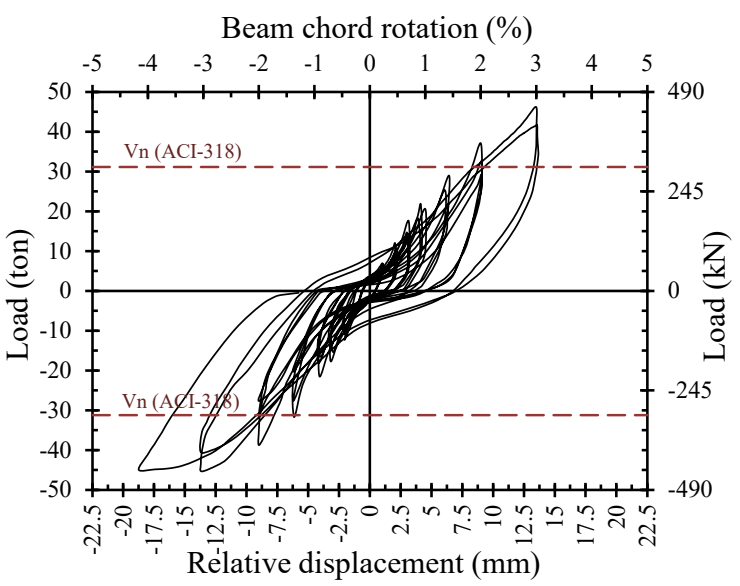

Figure 14: Load-displacement response for specimen LB13-00.

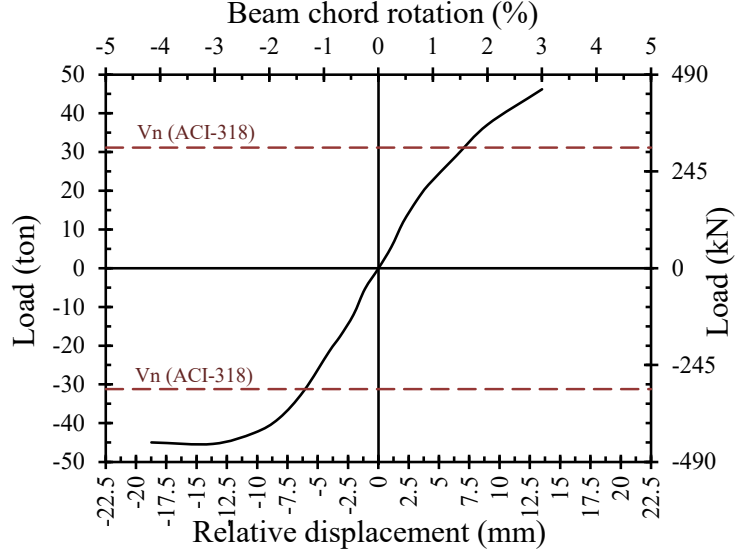

Figure 15: Envelope curve of loaddisplacement for specimen LB13-00. 


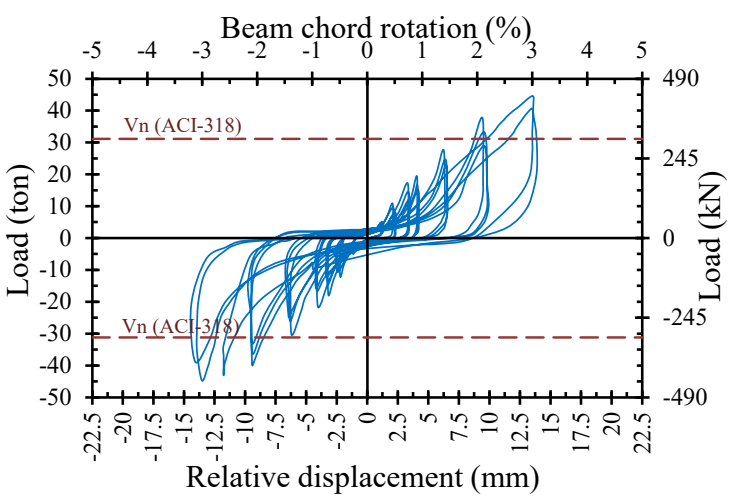

Figure 16: Load-displacement response for specimen LB13-TB.

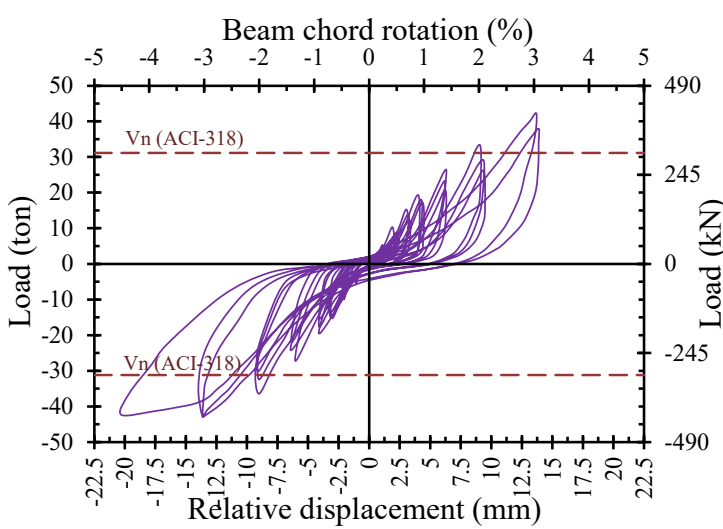

Figure 18: Load-displacement response for specimen LB13-RL.

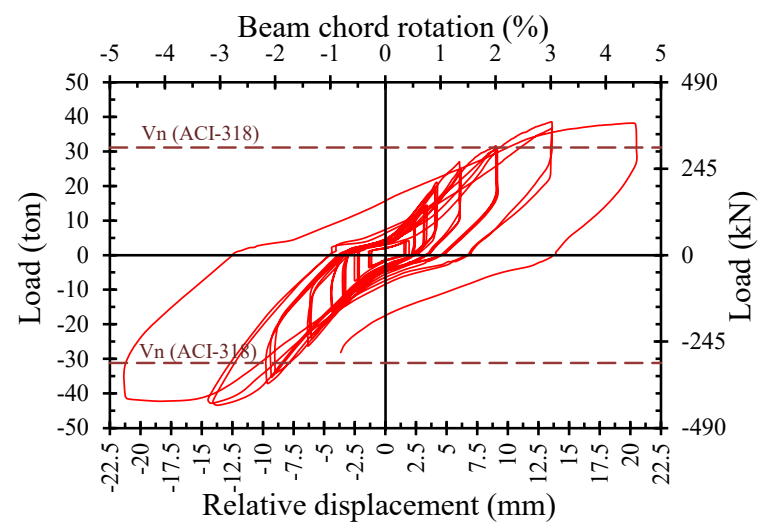

Figure 20: Load-displacement response for specimen LB13-TBRL.

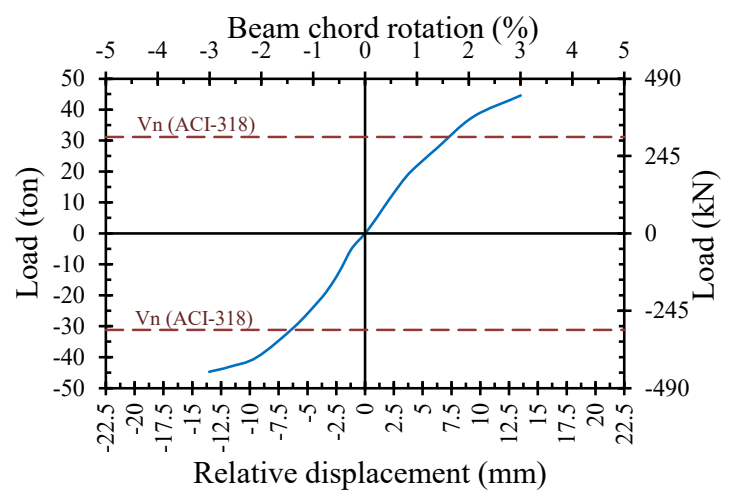

Figure 17: Envelope curve of loaddisplacement for specimen LB13-TB.

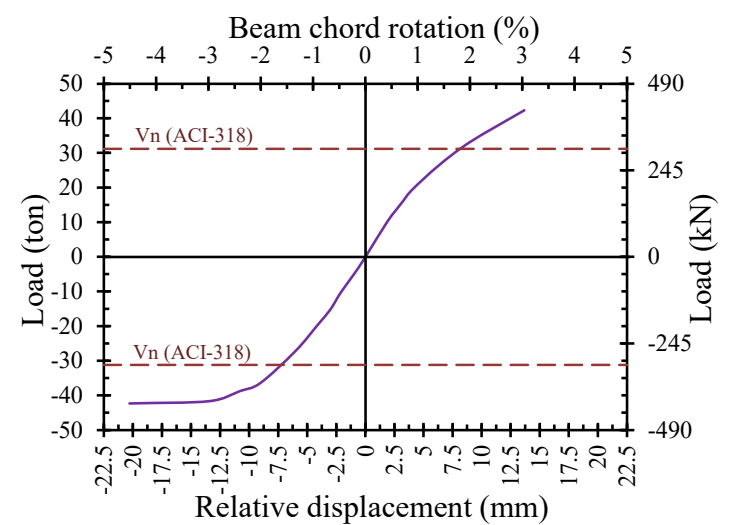

Figure 19: Envelope curve of loaddisplacement for specimen LB13-RL.

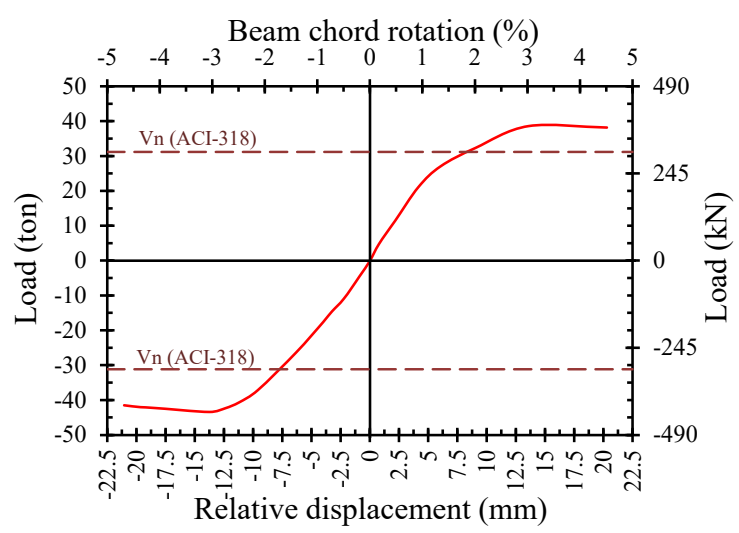

Figure 21: Envelope curve of loaddisplacement for specimen LB13-TBRL. 


\subsection{Comparisons of Load Displacement Relations}

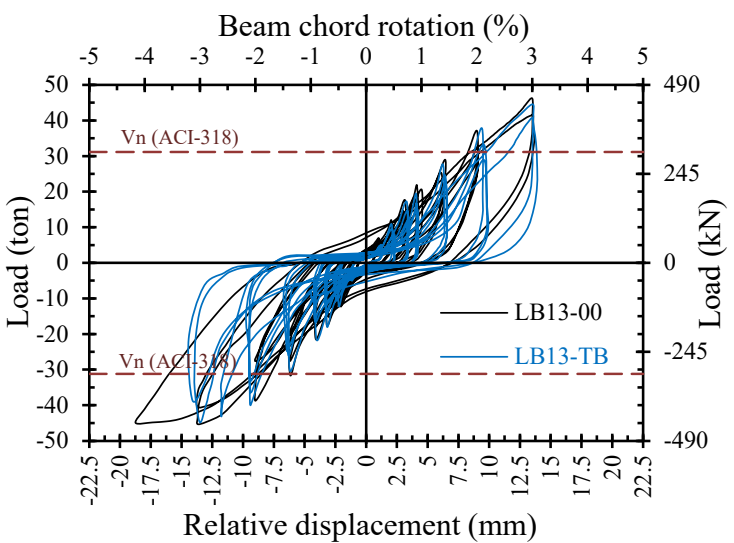

Figure 22: Load-displacement: LB13-00

vs. LB13-TB.

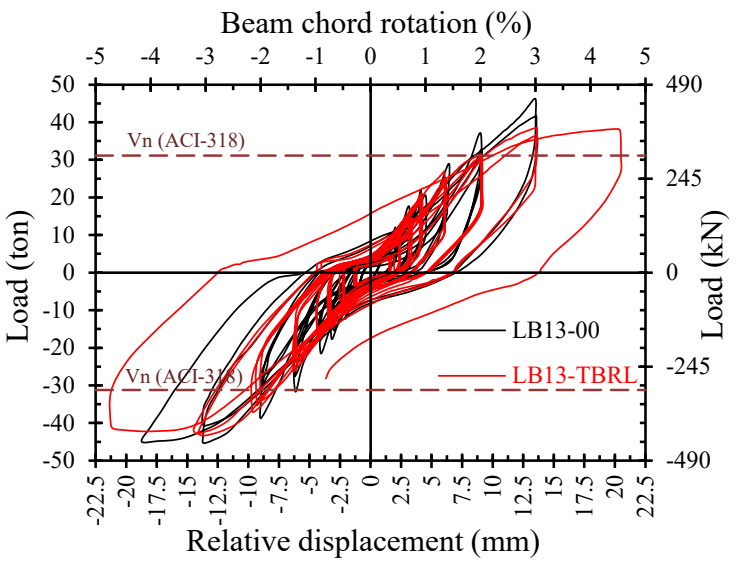

Figure 24: Load-displacement: LB13-00 vs. LB13-TBRL.

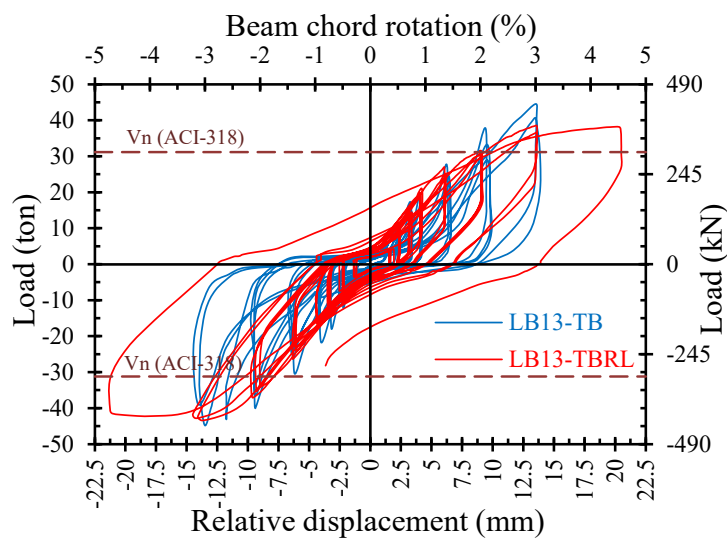

Figure 26: Load-displacement: LB13-TB vs. LB13-TBRL.

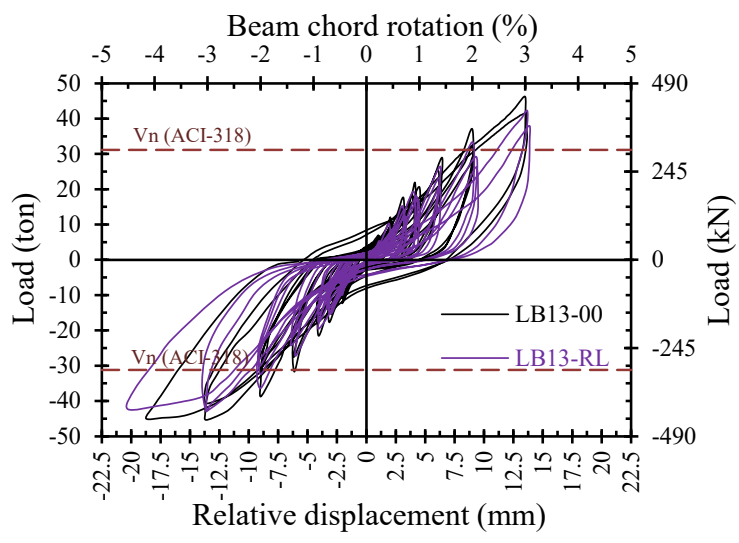

Figure 23: Load-displacement: LB13-00 vs. LB13-RL.

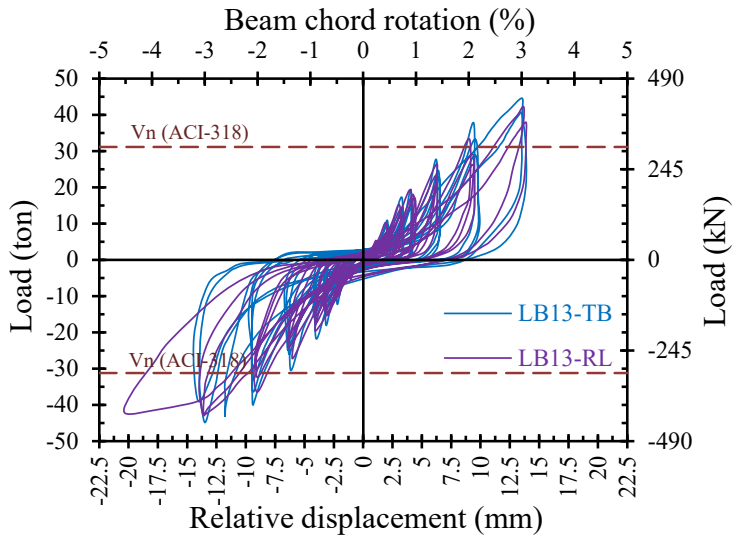

Figure 25: Load-displacement: LB13-TB vs. LB13-RL.

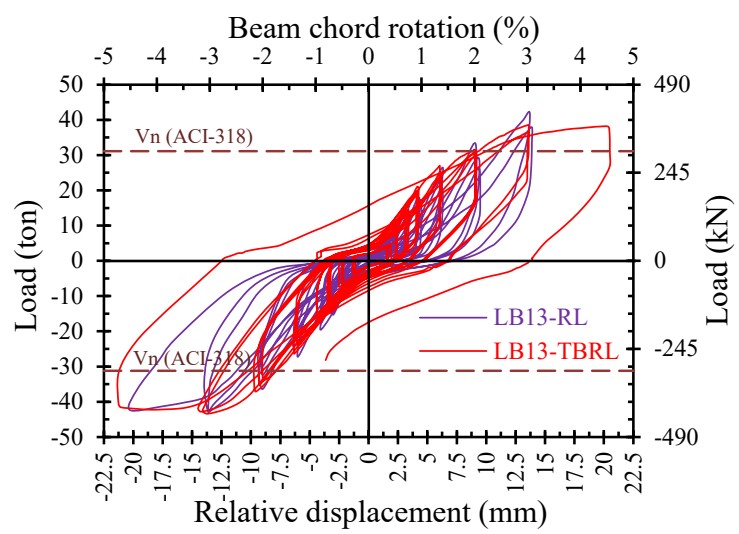

Figure 27: Load-displacement: LB13-RL vs. LB13-TBRL. 


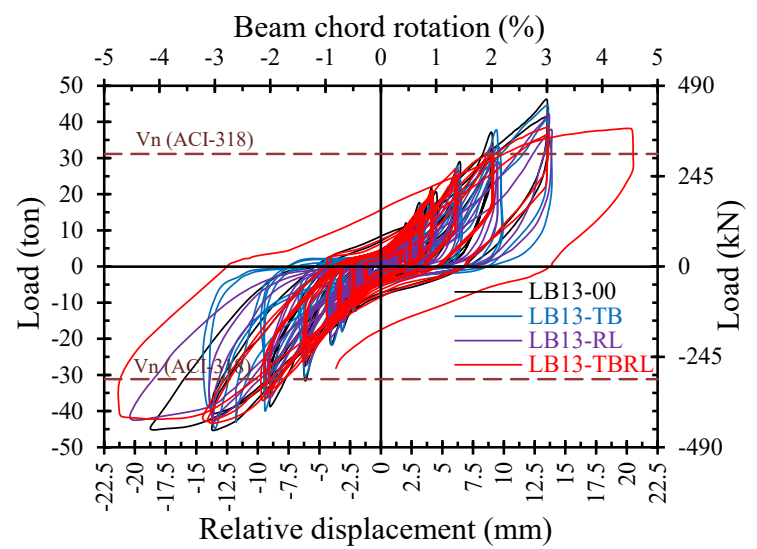

Figure 28: Load-displacement for all specimens.

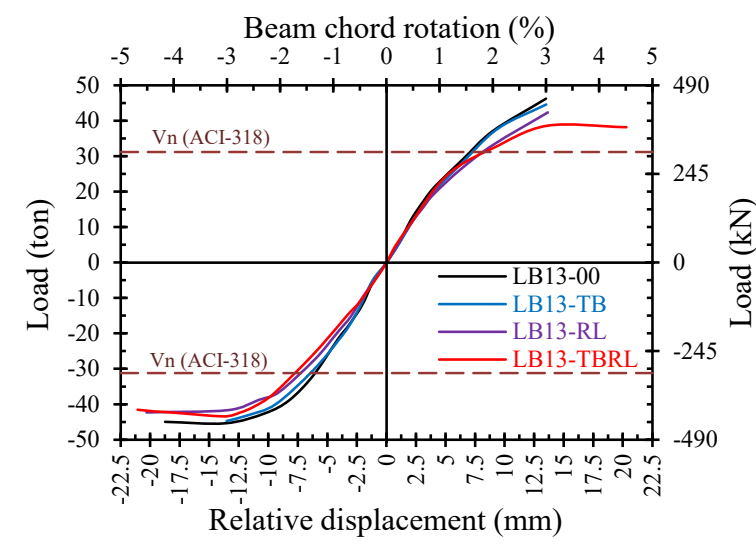

Figure 29: Envelope curves for all specimens.

\subsection{Loads at First Crack, Yield and Failure}

The four specimens were subjected to gradually increasing cyclic loading till displacement amplitude of each cycle occur. The theoretical value of shearing force $\mathrm{V}_{\mathrm{n}}$ of control specimen (LB13-00) is $305.48 \mathrm{kN}$ (31.15 ton.f) as calculated by ACI that achieves $0.745 \sqrt{f_{c}^{\prime}} \mathrm{A}_{\mathrm{cw}}$ shear strength and $68.73 \mathrm{kN} . \mathrm{m}$ corresponding bending moment at wall-beam interface. The resulted forces of these tests are summarized in Table 4, Figure 30 and Figure 31.

Table 4: Force results of tested specimens.

\begin{tabular}{|c|c|c|c|c|c|}
\hline \multirow[b]{2}{*}{ Specimen ID } & \multicolumn{3}{|c|}{ Load, V (kN) } & \multicolumn{2}{|c|}{ Shear strength coefficient, $\gamma(\mathrm{N}-\mathrm{mm})$} \\
\hline & $\begin{array}{l}\text { At first } \\
\text { crack }\end{array}$ & At yield & $\begin{array}{l}\text { Ultimate } \\
\text { load }\end{array}$ & $\begin{array}{c}\frac{V_{y}}{\sqrt{f_{c}^{\prime}} A_{c w}} \\
(\mathrm{~N}-\mathrm{mm})\end{array}$ & $\begin{array}{c}\frac{V_{\max }}{\sqrt{f_{c}^{\prime}} A_{c w}} \\
(\mathrm{~N}-\mathrm{mm})\end{array}$ \\
\hline LB13-00 & 135.3 & 396.30 & $453.26^{*}$ & 1.024 & 1.172 \\
\hline LB13-TB & 119.4 & 395.88 & 438.65 & 0.987 & 1.094 \\
\hline LB13-RL & 94.50 & 369.74 & 415.14 & 0.957 & 1.075 \\
\hline LB13-TBRL & 93.70 & 323.21 & 425.45 & 0.863 & 1.136 \\
\hline
\end{tabular}

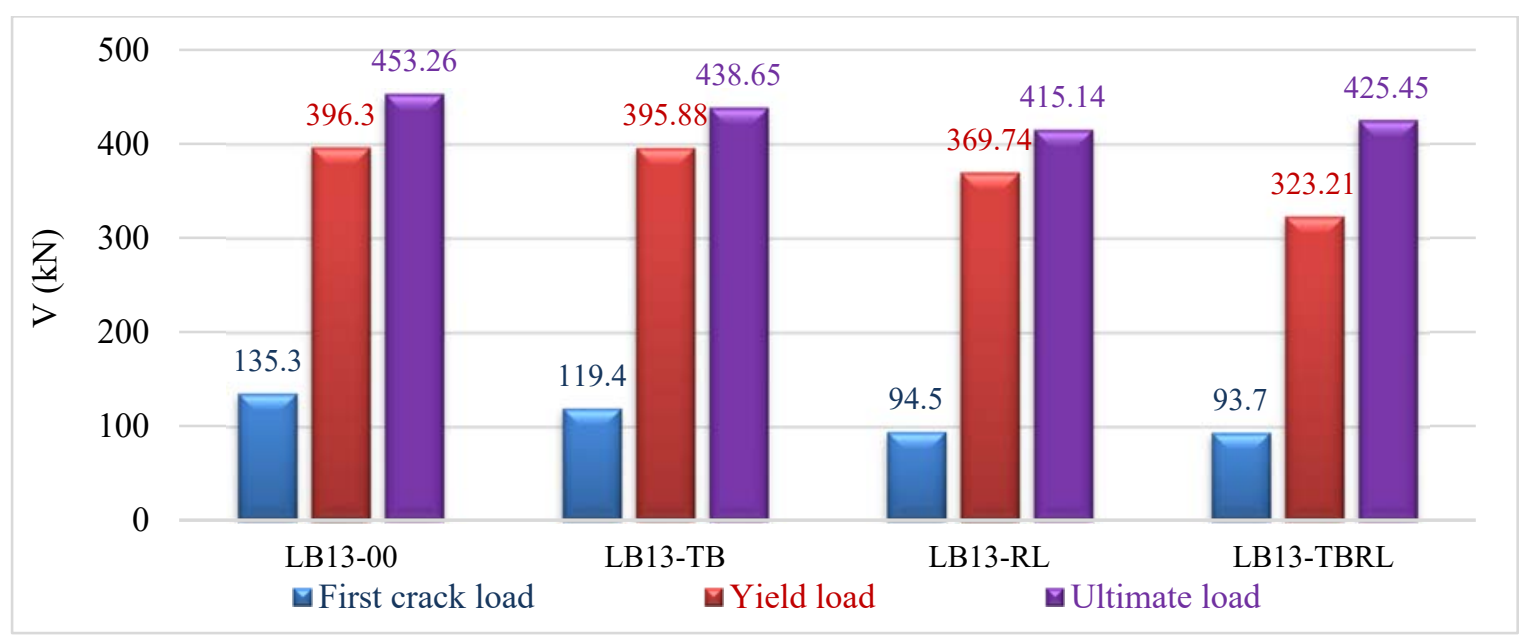

Figure 30: First crack, yield and ultimate loads for all test specimens. 


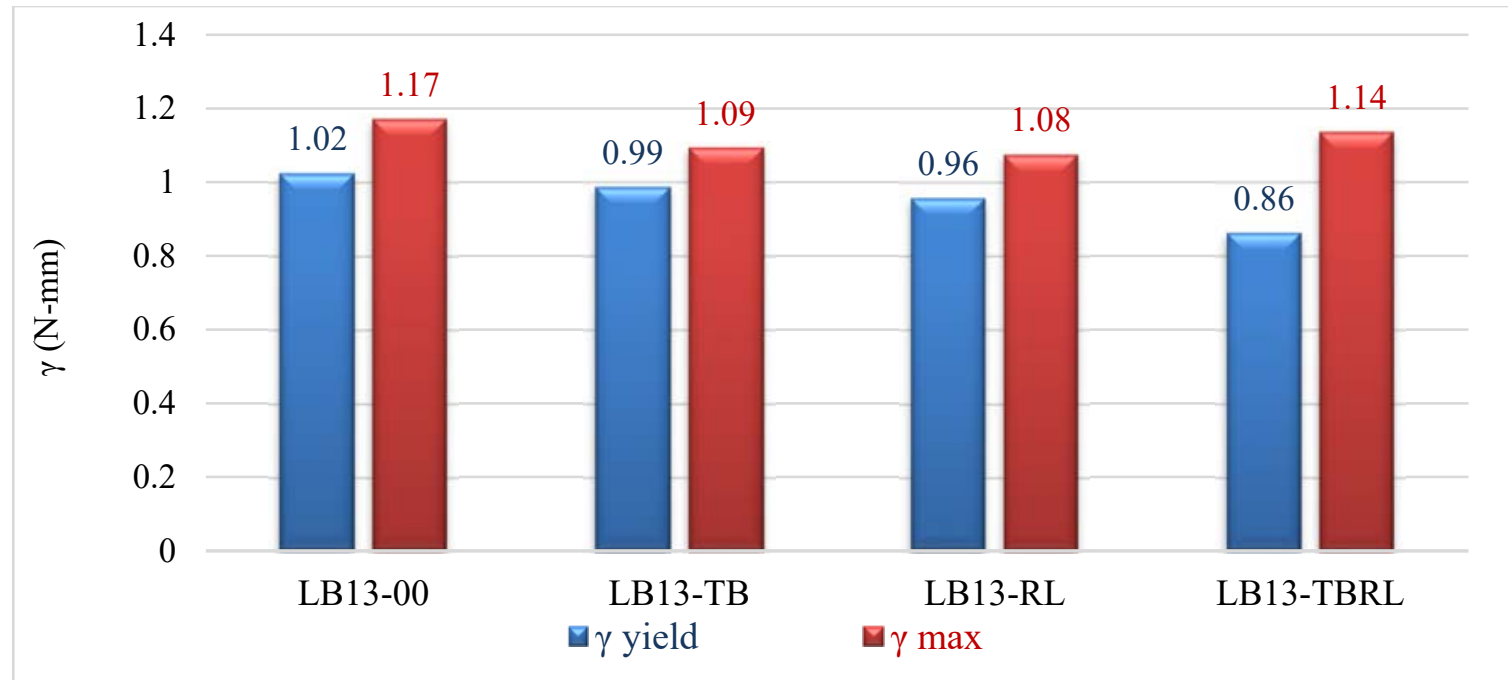

Figure 31: Shear strength coefficient at yield and ultimate stages.

\subsection{Ductility}

The displacement results are summarized in Table 5 for all tests. The ductility factor $\mu$ is calculated using two methods, the first method is the ratio between the ultimate and yield displacements (displacement ductility) as shown in Eq.4. To define yield displacement, a secant was drawn through the measured force displacement envelope at 0.75 times the maximum resistance; the intersection of that secant with a horizontal line at the maximum resistance defined the yield displacement. The procedure is illustrated in Figure 32, Figure 33, Figure 34 and Figure 35. The second method is as the ratio between the ultimate and yield energy (energy ductility) as shown in Eq.5.

Table 5: Relative displacement results of tested specimens.

\begin{tabular}{|c|c|c|c|c|c|c|c|}
\hline \multirow{2}{*}{ Specimen ID } & \multicolumn{3}{|c|}{$\begin{array}{c}\text { Relative displacement } \\
\Delta(\mathbf{m m})\end{array}$} & \multicolumn{2}{|c|}{$\begin{array}{c}\text { Chord rotation } \\
\boldsymbol{\theta}(\%) \\
\end{array}$} & \multicolumn{2}{|c|}{ Ductility $(\mu)$} \\
\hline & $\begin{array}{l}\text { At first } \\
\text { crack }\end{array}$ & $\Delta_{y}$ & $\Delta_{\boldsymbol{u}}$ & $\boldsymbol{\theta}_{y}$ & $\boldsymbol{\theta}_{u}$ & $\begin{array}{c}\text { Displacement } \\
\text { ductility }\end{array}$ & $\begin{array}{l}\text { Energy } \\
\text { ductility }\end{array}$ \\
\hline LB13-00 & 4.00 & 9.1160 & 18.742 & 2.03 & 4.16 & 2.06 & 1.27 \\
\hline LB13-TB & 3.00 & 9.6620 & 13.532 & 2.15 & 3.01 & 1.40 & 1.34 \\
\hline LB13-RL & 3.00 & 10.015 & 20.298 & 2.23 & 3.84 & 2.03 & 1.66 \\
\hline LB13-TBRL & 2.34 & 10.490 & 21.060 & 2.33 & 4.68 & 2.11 & 1.80 \\
\hline
\end{tabular}

$$
\begin{aligned}
& \mu_{\text {disp }}=\frac{\Delta_{u}}{\Delta_{y}} \\
& \mu_{E}=\frac{E_{u}}{E_{y}}
\end{aligned}
$$




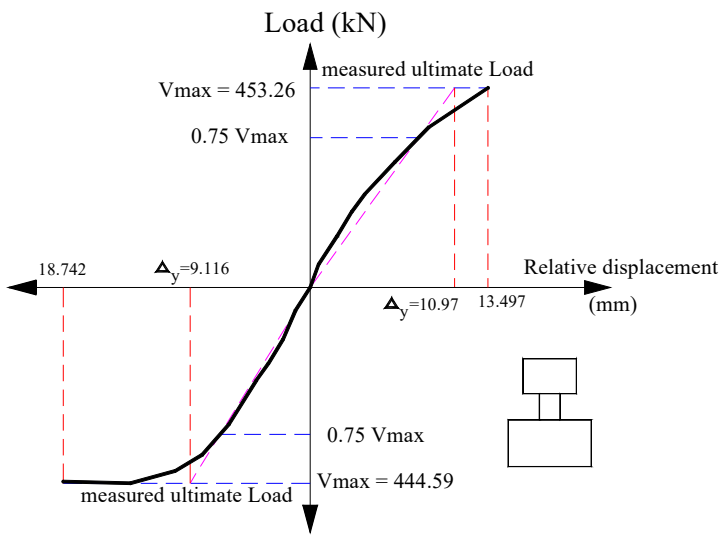

Figure 32: Ultimate and yield displacement for specimen LB13-00.

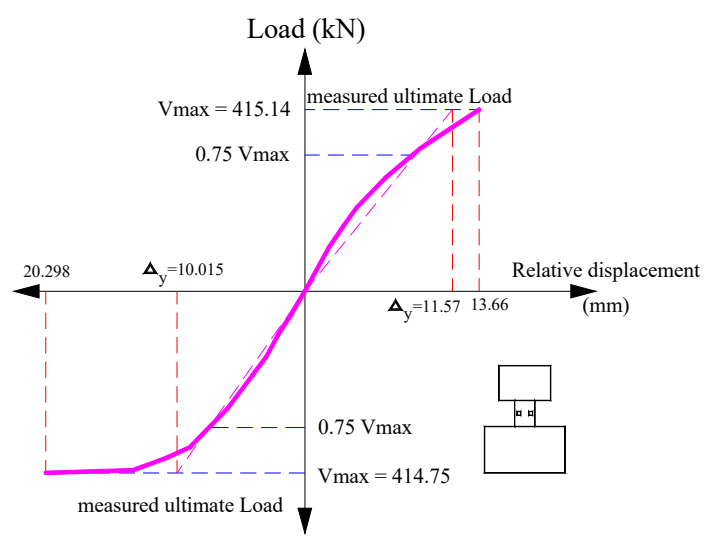

Figure 34: Ultimate and yield displacement for specimen LB13-RL.

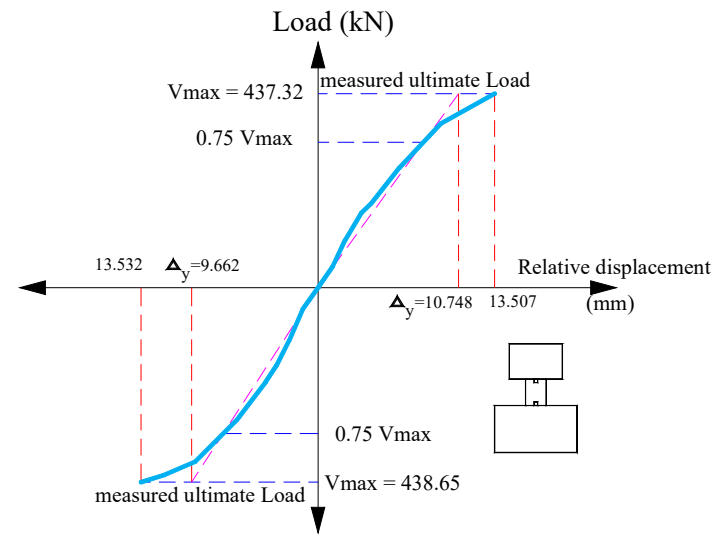

Figure 33: Ultimate and yield displacement for specimen LB13-TB.

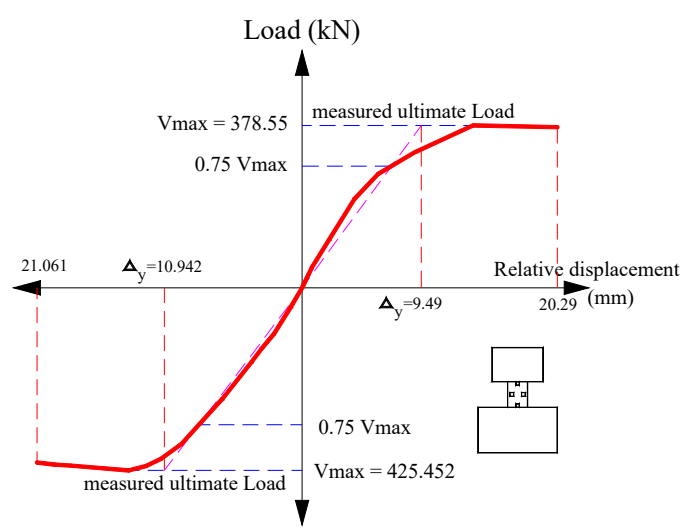

Figure 35: Ultimate and yield displacement for specimen LB13-TBRL.

\subsection{Effective Stiffness}

Stiffness degradation is a parameter used to evaluate the overall response of specimens. Figure 36 shows the method of calculation of stiffness at one of the cycles. The relation between beam chord rotation and corresponding effective stiffness for tested specimens are tabled in Table 6 and shown in Figure 37.

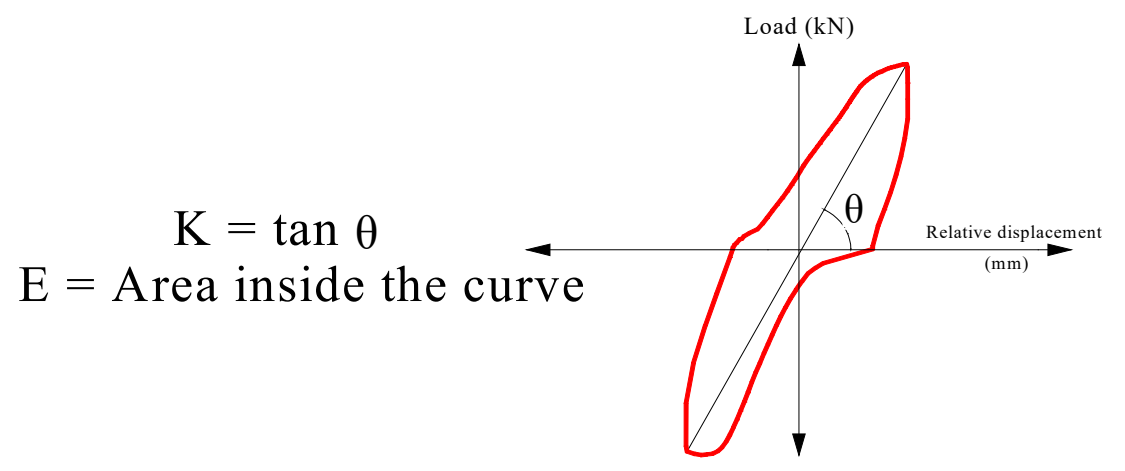

Figure 36: Calculation of effective stiffness and cumulative dissipated energy at a cycle. 
Table 6: Beam chord rotation and effective stiffness relation for tested specimens.

\begin{tabular}{|c|c|c|c|c|c|c|c|c|c|}
\hline \multicolumn{2}{|c|}{ Disp.(mm) } & $\mathbf{1}$ & $\mathbf{2}$ & $\mathbf{3}$ & $\mathbf{4}$ & $\mathbf{6}$ & $\mathbf{9}$ & $\mathbf{1 3 . 5}$ & $\mathbf{2 0 . 2 5}$ \\
\hline \multicolumn{2}{|c|}{$\boldsymbol{\theta}(\boldsymbol{\%})$} & $\mathbf{0 . 2 2}$ & $\mathbf{0 . 4 4}$ & $\mathbf{0 . 6 7}$ & $\mathbf{0 . 8 9}$ & $\mathbf{1 . 3 3}$ & $\mathbf{2 . 0 0}$ & $\mathbf{3 . 0 0}$ & $\mathbf{4 . 5 0}$ \\
\hline \multirow{3}{*}{$\begin{array}{c}\mathbf{K} \\
(\mathbf{k N / m m})\end{array}$} & $\mathbf{L B 1 3 - 0 0}$ & 56.33 & 57.08 & 54.44 & 51.42 & 47.28 & 41.30 & 33.08 & ---- \\
\cline { 2 - 10 } & LB13-TB & 42.09 & 52.96 & 53.01 & 49.90 & 45.74 & 40.56 & 32.40 & --- \\
\cline { 2 - 10 } & LB13-RL & 48.97 & 49.99 & 47.08 & 44.11 & 40.19 & 36.77 & 30.46 & 21.18 \\
\cline { 2 - 10 } & LB13-TBRL & 24.07 & 34.11 & 43.93 & 42.58 & 40.77 & 35.70 & 29.40 & 18.90 \\
\hline
\end{tabular}

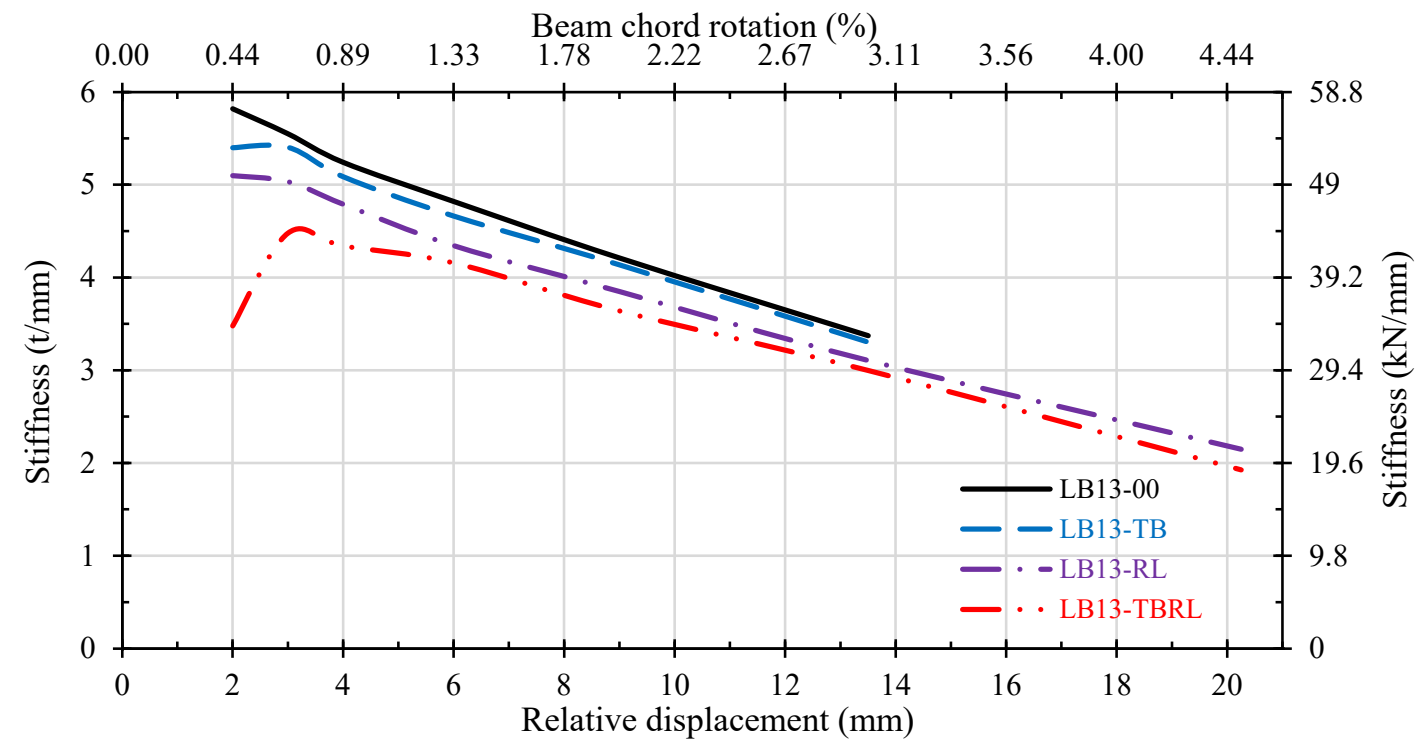

Figure 37: Stiffness degradation vs. chord rotation for all tested specimens.

\subsection{Cumulative Dissipated Energy}

The dissipated energy E of one cycle can be calculated using many methods. Here, the energy was calculated graphically as the area inside the closed curve of the cycle using the drawing program, AutoCAD as shown in Figure 36. The relation between rotation $\theta(\%)$ and cumulative dissipated energy $\mathrm{E}(\mathrm{kN} . \mathrm{mm})$ for the tested specimens are compared and tabled in Table 7 and shown in Figure 38.

Table 7: Beam chord rotation and cumulative dissipated energy relation for tested specimens.

\begin{tabular}{|c|c|c|c|c|c|c|c|c|c|}
\hline \multicolumn{2}{|c|}{ Disp.(mm) } & 1 & 2 & 3 & 4 & 6 & 9 & 13.5 & 20.25 \\
\hline \multicolumn{2}{|c|}{$\theta(\%)$} & 0.22 & 0.44 & 0.67 & 0.89 & 1.33 & 2.00 & 3.00 & 4.50 \\
\hline \multirow{4}{*}{ E (kN.mm) } & LB13-00 & 203 & 705 & 1926 & 3719 & 6769 & 10359 & 13154 & ---- \\
\hline & LB13-TB & 198 & 785 & 2072 & 3919 & 7544 & 11961 & 16011 & ---- \\
\hline & LB13-RL & 259 & 967 & 2597 & 4813 & 9120 & 14364 & 20514 & 23815 \\
\hline & LB13-TBRL & 381 & 1289 & 3148 & 5746 & 10370 & 16340 & 23699 & 29359 \\
\hline
\end{tabular}




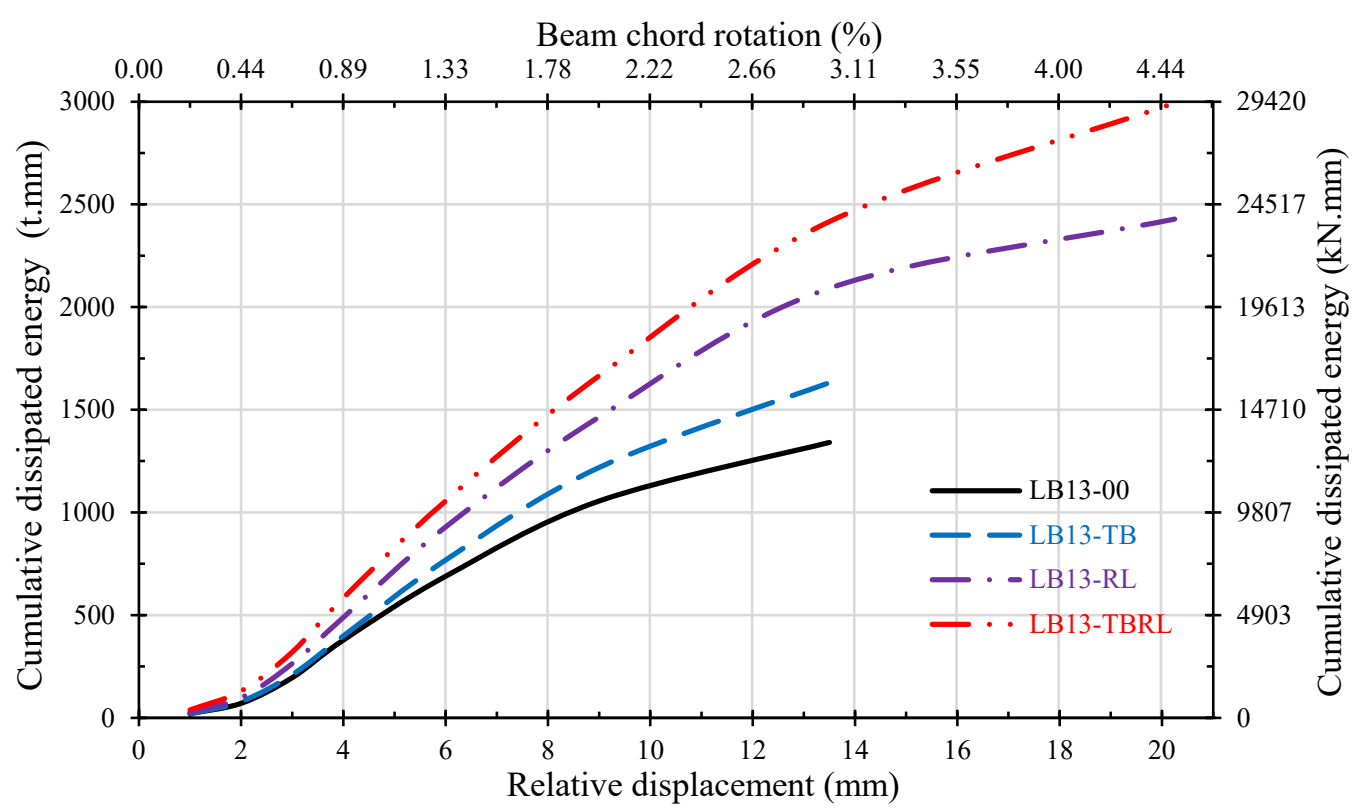

Figure 38: Beam chord rotation and cumulative dissipated energy for all tested specimens.

\section{CONCLUSION}

The analysis and discussion of the test results lead to the following conclusions:

1. The overall behavior of coupling beam with low span to depth ratio $(\mathrm{Ln} / \mathrm{h}=1.29)$ showed a good coupling link between their shear walls where as the formed cracks are mainly diagonals (shear cracks).

2. The overall behavior and cyclic shear force capacity of the coupling beams decreases if the beams contain some openings than that without openings.

3. Using two openings located at top and bottom of the beam (according to the beam position during the test) slightly reduces the stiffness of the beam compared to specimen without openings by $3.5 \%$ approximately.

4. Using two openings in coupling beams with aspect ratio of 1.29 and located at right and left of the beam (according to the beam position during the test) reduces the beam stiffness by $\sim 5 \%$ more than using openings located at top and bottom.

5. Using four openings in coupling beams with aspect ratio of 1.29 reduces the stiffness of the beam by $\sim 13.5 \%$ approximately.

6 . The presence of the openings in the diagonally reinforced coupling beams which are designed in according to the ACI-318-19 ${ }^{[1]}$ with aspect ratio of $\mathrm{Ln} / \mathrm{h}=1.29$, reduces the shear capacity consequently the stiffness of the coupling beams. Stiffness reduction percentage is relatively high at small rotations $(\sim 0.44 \%)$ and decreased at larger rotations $(\sim 2 \%)$.

7. The cumulative dissipated energy increases in the case of using two openings and in the case of using four openings further increase in energy dissipation $(\sim 80 \%)$ was observed. 


\section{REFERENCES}

1) ACI Committee 318, 2019, "Building Code Requirements for Structural Concrete (ACI 318M-19) and Commentary (318RM-19)," American Concrete Institute, Farmington Hills, Mich.

2) American Society of Civil Engineers, 2007, “ASCE/SEI Standard 41-06, Seismic Rehabilitation of Existing Buildings," Reston, VA.

3) Bhunia D., Prakash V. and Ashok D. P., 2013, “A Conceptual Design Approach of Coupled Shear Walls" Hindawi Publishing Corporation, ISRN Civil Engineering, Volume 2013, Article ID 161502.

4) Bower, O., 2008, "Analytical Investigation into the Effect of Axial Restraint on the Stiffness and Ductility of Diagonally Reinforced Concrete Coupling Beams," MS Thesis, University of Cincinnati, $108 \mathrm{pp}$.

5) ECP Committee 203, 2018, "Design and construction of concrete structures (ECP 203-2018)".

6) Elwood, K.J., et al., 2007, "Update to ASCE/SEI 41 Concrete Provisions," Earthquake Spectra, EERI, Vol. 23, Issue 3, pp. 493-523.

7) Elzeiny, S.M., 2007, "BEHAVIOR OF BOTTOM LOADED SIMPLY SUPPORTED DEEP BEAMS WITH SQUARE WEB OPENINGS", Housing and Building National Research Center, Cairo, Egypt.

8) ENR, 2007. "Good News for Tall, Concrete Cores," story by Nadine Post, Engineering News Record, 16 May 2007, pp. 10-11.

9) Fortney, P., 2005, “The Next Generation of Coupling Beams," PhD Dissertation, University of Cincinnati, $370 \mathrm{pp}$.

10)Hassan, W.M., 2011, "Analytical and Experimental Assessment of Seismic Vulnerability of Beam-Column Joints Without Transverse Reinforcement in Concrete Buildings" Doctoral dissertation, University of California, Berkeley, $998 \mathrm{pp}$.

11)Naish, D., 2010, "Testing and Modeling of Reinforced Concrete Coupling Beams," Doctoral dissertation, University of California, Los Angeles.

12)Tuna, Z., 2009, "Quantification of Seismic Performance Levels of Tall Buildings," MS Thesis, University of California, Los Angeles, pp.135.

13)Wallace, J. W., 2007, "Modeling issues for tall reinforced core wall buildings," The Structural Design of Tall and Special Buildings, V. 16, No. 5, pp. 615-632.

14)Whan S. H., Hyeyoung Koh and Chang Seok Lee (2019), “Accurate and Efficient Simulation of Cyclic Behavior of Diagonally Reinforced Concrete Coupling Beams," Earthquake Spectra, Volume 35, No. 1, pages 361-381, February 2019; Earthquake Engineering Research Institute. 